\title{
TRENDS IN EDUCATIONAL PSYCHOLOGY IN JAPAN IN 1989
}

\author{
Seisoh SUKEMUNE \\ (Hiroshima University)
}

I. Annual Convention.

1. Paper Presentations.

2. Symposia and Invited Talks.

II. Publications.

1. The Japanese Journal of Educational Psychology.

2. The Annual Report of Educational Psychology in Japan.

III. Educational Psychology Today in Japan.

1. Current Topics of Symposia.

2. Current Reseach Topics at Each School Level.

3. Faces of Educational Psychology.

IV. References.

\section{Annual Convention.}

1. Paper Presentations.

The 31st Annual Convention of the Japanese Association of Educational Psychology was held at The University of Hokkaido, July 26 through 28, 1989, under the General Chair, Professor Kazuo Miyake.

Table 1 shows the number of presentations in each area.

\section{Table 1}

The number of presentations at the 31st Annual Convention of Japanese Association of Educational Psychology (1989)

\begin{tabular}{lrr}
\hline \hline Areas & \multicolumn{2}{c}{$\begin{array}{c}\text { Number of } \\
\text { Presentations }\end{array}$} \\
\hline Developmental & 198 & 43.52 \\
Instructional Process. & 53 & 11.65 \\
Personality & 48 & 10.55 \\
Learning & 48 & 10.55 \\
Social & 37 & 8.13 \\
Handicapped and Disorders & 29 & 6.37 \\
Measurement and Evaluation & 26 & 5.71 \\
Clinical & 12 & 2.64 \\
Theory and Methodology & 4 & 0.88 \\
\hline Total & 455 &
\end{tabular}

As seen. in Table 1, the area of developmental research accounts for almost half of all presentations. Instructional process is the second on the list. Both personality and learning account for about 10 persent each. This trend of the number of individual presentations in each area has not changed over the past decade. Thus, developmental research occupies a very important position actually not only in educational psychology but also psychology in general here in Japan.

\section{Symposia.}

As usual, three different kinds of symposia were held. They were (1) symposia planned by the Local Executive Organizing Committee, (2) symposia planned by the Research Committee of the Japanese Association of Educational Psychology, and (3) symposia planned by members themselves independently sponsored. The General Chair of this annual convention, Professor Miyake, has been doing much research on human development from the mother-child interactional point of view. He has explored the nature of human development for a long time, and the symposia planned by the Local Executive Organizing Committee greatly concerned with this point.

(1) Symposia planned by the Local Excutive Organizing Committee.

(a) Exploring paradigms of developmental psychology reseach: Towards better human understanding (organized by Tamotsu Fujinaga).

(b) Pioneers of child development research in Japan : Significance of their work today (organized by Kazuo Miyake).

(c) On the school-aged children's adaptation to school: Critical situation concerning modern child (organized by Eiji Murakami).

(2) Symposia planned by the Research Committee of Japanese Association of Educational Psychology.

In the Japanese Association of educational Psychology there is a special committee regarding research which is called the Research Committee. The follow. 
ing three symposia were planned by this committee.

(a) Exploring new forms of instruction and classes (organized by Kazuma Haraoka).

(b) What do expert studies suggest for education? (organized by Giyoo Hatano).

(c) Bringing up self-educability and its reconsideration (organized by Takashi Muto).

(3) Symposia independently planned by members themselves.

Symposia held in Japan have been planned generally by the Local Executive Organizing Committee, and symposia planned by members themselves independently have been called generally "Jishu (independent) Symposia." This "Jishu Symposia" seem to be a barometer of the association members' current research interests and topics.

There are many different topics, but an increasing concern is to hold symposia dealing with early childhood education more and more. The following twelve symposia planned independently by member themselves were held.

(a) Developmental studies of space perception and its problem (organized by Akira Katsui).

(b) Perspectives of item trait theory (organized by Hiroshi Watanabe).

(c) How do we grasp the individual differences in developmental studies: On individual difference studies in Japan (organized by Hiroshi Usui).

(d) Outcomes and perspectives of sentence comprehension studies (organized by Nobuko Uchida).

(e) School problem corresponding to school refusal (organized by Eiji Koizumi).

(f) On "children's nature" in developmental studies and educational practices: Developmental studies helpful for early childhood education and care, and developmental studies requested by early childhood education and care (organized by Kunio Wakai).

(g) On the "science of play" (organized by Tamaki Takahashi).

(h) Themes of integration in early childhood education and care (organized by Yoshiaki Mitani).

(i) Themes of death education today in Japan (organized by Kumiko Murayama).

(j) The role of neuropsychology in developmental studies (organized by Noboru Sakano).

(k) Cognitive science and instructional science (organized by Michio Baba).

(1) On the future of language development studies (organized by Shizuo Iwatate).

(4) Invited Talks.

There were two invited talks. Professor Zhao Lan of Peking University, China, gave his talk on "the organizational function of different emotions on task performance." Professor Joseph J. Campos of The University of California, Berkeley, USA, gave his talk on "new trends on emotion theory and temperament in infancy : Implications for cross-national research."

\section{Publications.}

There are two kinds of prominent periodicals reqularly published. One is the Japanese Journal of Educational Psychology written in Japanese with English abstract. The other is the Annual Report of Educational Psychology in Japan written in Japanese, except for "Trends in Educational Psychology in Japan" written in English.

1. The Japanese Journal of educational Psychology.

The number of original articles and brief notes published by the Japanese Journal of educational Psychology (numbers 1, 2, 3 and 4 of volume 37; March 1989 through December, 1989) is shown in Table 2.

Table 2

The number of original articles and brief notes published by the Japanese Journal of Educational Psychology (numbers 1, 2, 3 and 4 of volume 37 ; March 1989 through December, 1989)

\begin{tabular}{ccccc}
\hline \hline Volume & Number & Original Articles & Brief Notes & Review \\
\hline 37 & 1 & 6 & 5 & 1 \\
37 & 2 & 5 & 7 & - \\
37 & 3 & 6 & 7 & - \\
37 & 4 & 6 & 7 & - \\
\hline & Total & 23 & 26 & 1
\end{tabular}

2. The Annual Report of Educational Psychology in Japan.

Volume 28 of the Annual Report of Educational Psychology in Japan was published in March,1989. This volume consists of the following seven chapters.

I. Brief outlines of the 30th Annual Convention of 
the Japanese Association of Educational Psychology held at Naruto University of Teacher Education (November 24 through 26, 1988). Here the summaries of nine symposia planned by the Local Executive and Organizing Committee of this annual convention have been described.

(a) Educational psychology towards the 21st century: Exploring our new development (organized by Motomi Kishida and Chizuko Asami).

(b) Trends and problems in research on the tesching-learning process (organized by Shizuko Yoshizaki and Michiharu Tanaka).

(c) On the contribution of fundamental psychology to educational psychology (organized by Michihiko Matsuda, Machiko Sannomiya, and Hiroshi Kume).

(d) Child psychology and children's literature (organized by Hiroko Sasaki).

(e) Education under stress (organized by Yoshida Kurato).

(f) Psychology and problems concerning women psychologists (organized by Yasuyuki Sasaki).

(g) On the internal-external locus of control (organized by Sanshiro Shirakashi).

(h) Development, education and care of altruistic behavior (organized by Fumiko Matsuda, Iwao Hashimoto, and Seisoh Sukemune).

(i) To what extent can educational psychology contribute to the education for autistic children? (organized by Yoshihito Ito and Hisako Onishi).

Brief summaries of the following two symposia planned by the Research Committee are described here :

(a) On the new school subject, "life environmental studies (chaired by Eiichi Kajita).

(b) On Teacher's career development (chaired by Yukiko Takeshita).

II. Studies in educational psychology in Japan over the past year

Development (from infancy to adulthood), personality, social development, instruction and learning, measurement and evaluation, clinical and handicapped.

III. Trends in educational psychology in Japan (by Kazuo Miyake, Takashi Furutsuka, Hiroshi Usui,
Kimiharu Sato, Mari Aoki and Shigeru Nakano).

IV. Overviews on current research topics:

(1) Empathy and its development (by Keisuke Sawada).

(2) Personal theory of learning instruction (by Masami Kajita and Setsuko Ishida).

V. Summaries of doctoral dissertations submitted to thirteen universities, and the themes of Master's theses in the field of educational psychology submitted to the about forty universities.

VI. Literature related to educational psychology (published in Japan).

VII. Brief regional review reports on original articles and brief notes published by the Japanese Journal of Educational Psychology (number 4 of volume 35, and numbers 1, 2, 3 and 4 of volume 36 ).

\section{Educational Psychology Today in Japan.}

1. Current Topics of Symposia.

(1) Developmental Studies.

What is development? This is an old but new topic not only in educational psychology but also in general psychology. It might be said that research outcomes are inevitably derived from the methodology used. The same rule probably applies to many developmental studies. In the Miyake's symposium, Taro Sonohara, Kanji Hatano and Mantaro Kido were considered as the pioneers of child development research in Japan. If the present author would be asked, he would add Ryoei Kubo to these three pioneers. Fujinaga's symposium regarding the paradigms of developmental psychology research was proper from both theoretical and metodological points of view. Hatano's symposium was also concerned with the nature of child development. In the Wakai's symposium, participants referred to "children's nature" from the viewpoints of developmental studies and educational practices. Usui's symposium theme was individual differences in developmental studies. The nature and characteristics of developmental studies were also considered in both Sakano's and Iwatate's symposia. More research on development or child development is needed, theoretically and methodologically, in many aspects of educational psychology. More research on life-span approaches to development or child development 
should be done.

(2) School Education.

There were many symposia regarding school education and its related topics. Muto and Kitao organized a symposium on self-educability. This is a very important topics in school education, and school education should be reconsidered from this viewpoint. Haraoka's symposium on the exploration of the new forms of instructions and classes in schools had to do with this viewpoint. A few symposia were concerned with school-aged children's adaptation to schools. They were Murakami and Kijima's symposia. The former topic concerned school adaptation, and in the latter school refusal was discussed.

(3) Early Childhood Education and Care.

An increasing concern in educational psychology is early childhood education and care. In the Takahashi's symposium participants discussed children's play. Mitani's symposium theme was concerned with integration or mainstreamed teaching in early childhood education and care.

(4) Fundamental Studies

In the Katsui symposium, space perception was discussed, and Watanabe's symposium theme was item trait theory. Sentence comprehension was discussed in Uchida's symposium. In Baba's symposium, participants discussed the possibility and limit of cognitive science. Maruyama's symposium was concerned with "death education" in Japan.

As seen here, symposia areas involved research on development, research on school adaptation and care, research on early childhood education and care, and research on basic and specific topics.

2. Current Research Topics at Each School Level. Only the original articles and brief notes published by the Japanese Journal of Educational Psychology (volume 37) are cited in this section. These articles and notes can be categorized in many ways, but here the present author has categorized these works into school levels. They are Infant Studies, Early Childhood Studies, School-aged Children Studies, Adolescent and Adult Studies, and Aged Adult Studies. In addition, two mentally retarded studies, two measurement and statistics studies, and a teacher study are also cited.

(1) Infant Studies.
Only three infant studies were published. Yamane (1989, 37, 345-352) examined the integrating process of the communicative mode in demanding situation during preverbal period. She found that acquisition of "pointing" in a preverbal period coincided with the establishment of a developmental basis in intentional operation of multiple sensory modalities. Sogon et al. (1989, 37, 353-358) .worked on mothers' emotional expression styles and thirteen-month-old infants' emotional behavior. Mothers were divided into four groups according to the scores on factor loadings of their expression styles : Expressing both negative and positive emotions $(\mathrm{N}+\mathrm{P}+)$, suppressing both negative and positive emotions $(\mathrm{N}-\mathrm{P}-$ ), expressing negative emotions and suppressing positive emotions $(\mathrm{N}+\mathrm{P}-)$ and suppressing negative emotions and expressing positive emotions $(\mathrm{N}-\mathrm{P}+)$. The $\mathrm{N}-\mathrm{P}+$ mothers saw their infants as expressing their emotions more lively, the $\mathrm{N}+\mathrm{P}-$ mothers considered their infants' emotions more suppressively, the $\mathrm{N}-\mathrm{P}-$ mothers considered their infants to be inclined to restrict their emotions and the $\mathrm{N}+\mathrm{P}+$ mothers considered their infants to behave more shyly. Taira et al. (1989, 37, 392-399) worked on the measurement of infants' and toddlers' language comprehension by an adaptive questionnaire. They found that accuracy of the questionnaire was kept a high level in spite of the fact that about two third of the items remained unanswered. The relationship of chronological age and the estimated ability levels might be regarded as linear. Although it is hard for us to find infant subjects, more research on infants is needed. For example, infants' cries and imitative responses should be studied more.

(2) Early Childhood Studies.

Early childhood studies here, roughly, consists of studies regarding (a) children's picture books, (b) learning to read and handwriting skills, (c) children's drawings, (d) visual perception, and (e) other specific topics.

(a) Picture Books.

Toyama (1989, 37, 151-157) studied maternal speech in mother-toddler picture book reading. The analysis of mothers' stategies of reading labels in the books showed that their strategies did not strictly correspond with children's comprehension level, but that their 
speech always included labels in some phases of the reading cycle. Mothers gave opportunities to hear again the label of the thing children had misnamed in the preceding cycle. Classifying mothers' speech suggested that in picture book reading mothers gave children various informations about print, category, story, book-handling, moral, and discipline. Furuya and Tashiro (1989, 37, 252-257) investigated the changes occurring while listening to a picture book. They found the duck was more appealing to children showing a certain identification and a more sympathetic feeling with the duck than the fox.

(b) Learning to Read and Handwriting Skills.

Haryu (1989, 37, 264-269) investigated the relative difficulty in learning to read "kanji" and "hiragana" by children. She found that the difficulty in learning characters depends not so much on their visual complexity as on the meaningfulness of their pronounciation. Onose (1989, 37, 186-190) investigated the effect of copying practices in different size on handwriting skills. He found that copying practices changing the size from large to normal were the most effective method of handwriting skill acquisition for handwriting beginners.

(c) Children's Drawings.

Matsumura (1989, 37, 225-233) examined whether preschool children can draw the faces of a cylinder and an occluded roof with visual realism. Most 5-year-olds drew separation correctly, but they also drew vertical separation when presented partical occusion or total occlusion. Most 6-year-olds could draw with visual realism. Uchida (1989, 37, 327-336) examined the role of "deficit-complement" schema played in a semantic integration of narrative sequences and the development of the same schema. The results showed that the hypothesis," the deficit information facilitating semantic integration of narrative sequences," was supported. She also found qualitative differences of the cognitive basis for story production between 4year-olds and 5-year-olds.

(d) Visual Perception.

Fujimoto (1989, 37, 337-344) investigated the relation between egocentrism in perspective taking task and intellectual realism in children's drawing. $\mathrm{He}$ concluded that egocentrism and intellectual realism were both parts of children's expression of the reality of an object. A developmental study of segregation in visual perception of figures was done by Kitahara (1989, 37, 198-207). She investigated the characteristics of segregation by preschoolers and examined how the visual perception of figures develop. She found that the segregation by preschoolers was less consistent across the conditions while more bound by the qualities of stimulus.

(e) Other Specific Topics

Yoshimizu (1989, 37, 1-10) investigated the development of symbolic play and its relation to language development and mother-child communication in the third year child. Sugimura (1989, 37, 179-185) examined how 3-and 4-year-old children understood the movement of covered objects. Fujita (1989, 37, 135143) investigated the mechanism of emergence and development of the synchrony pattern demonstrated between the child' sand the adult's verbalizations and hand-arm actions in "Janken-po" (stone, hand, scissors). Tsukamoto (1989, 37, 208-217) investigated the effects of children's lenient personal standards, stringent social standards and performance levels on their self-rewards criteria.

Surprisingly, the present author was unable to find research on morality, prosocial behavior or altruistic behavior such as helping, sharing, donating, and comforting. More research on these topics should be done in the field of educational psychology.

(3) School-aged Children Studies.

School-aged children studies are rich in variety as far as the topics are concerned. Among the studies, the present author takes up (a) abacus and arithmetic studies, (b) motivation, and (c) other specific topics.

(a) Abacus and Arithmetic Studies.

Hatta and Kanba (1989, 37, 320-326) investigated the effects of abacus training on cerebral functioning using a time-sharing method. They found that (1) in the mental calculation condition key-tapping tended to interfere more with the left them the right hand for both the experts and moderates, whereas interference was greater with respect to the right rather than the left hand for the beginners, and (2) in the verbal condition key-tapping greatly interfered with the right hand for all three groups. The results suggest that abacus 
training invited the right hemisphere contribution in mental calculation. Tajika and Ishida (1989, 37, 126134) - investigated how problem types and children's ability in solving word problems influence recall performance based on activity during problem presentation. They found that subjects who solved word problems recalled as many sentences about relations among variables as those who memorized them. Moreover, subjects who soved hard word problems increasingly made more recall errors of sentences about relations than those with correct performance. These results suggested that subjects with correct performance understand integrated semantic structure in solving word problems. Hosaka (1989, 37, 259-263) carried out a study regarding the influential process of confidence, performance and causal attribution in arithmetic. He found that (1) both confidence and performance had significant effects on division performance, and (2) ability attribution for success was the most important factor as an informational resource of both confidence and performance.

\section{(b) Motivation}

Sakurai (1989, 37, 29-35) investigated the effects of the instruction of evaluation and the expectation of extrinsic motivation. From the two experiments, he reconfirmed his previous model, the Self Evaluation Motivation (SEM) Model. Nakayama (1989, 37, 276282) examined how socially and task-oriented children percieve their teacher's attitude toward them. $\mathrm{He}$ found that socially oriented groups, especially $\mathrm{HH}$ group (both orientations being high) perceived teacher as giving more advice and direction, and receiving more information from a teacher. In contrust, $\mathrm{LH}$ group (task-orientation being dominant) tended not to receive their teacher's directive information.

(c) Other Specific Topics.

Niwa (1989, 37, 11-19) examined the attributionaffect processes in acheivement-related contexts among school-aged children. She found that causal attribution and causal dimension had both joint and independent effects on affective reactions. Watanabe (1989, 37, 163-171) investigated school-aged children regarding the relationship of development between distributive justice and authority. Her results showed that children's authority levels were closely associated with age, and their justice levels. It was suggested that children's developmental status on the sequence of justice levels were somewhat in advance of their progress on the authority levels. Kinoshita (1989, 37, 144-150) examined determinants of strategy choices in deciding order of performance for a group. She found that while the fifth graders discriminated the difference in importance among the issues to be decided, they did not change their strategies. Sugie and Kajita (1989, 37, 381-385) studied the peer-tutoring effect on teaching children. They found that (1) the learning set to teach another person "after one has learned" had positive effects on academic acheivement, and (2) the activities to teach another person seemed to have the posibility of raising some positive effects. A study of the process of sharing in children's play was done by Anan (1989, 37, 218-224). She explored how children made their own rules and shared them with peers in their play. She found that the higher the grade, the more aspects (self, others, rules) children would consider in beginning to play. Watanabe and Yamamoto (1989, 37, 286-292) made the Sentence Completion Test (SCT) of ego development for Japanese boys and girls, basing it on the Loevinger's WU-SCT. Shiomi and Nakashima (1989 , 37, 55-60) investigated the development of ability of mental retardation by children and its relationship with mental activities. The results showed that there were development progresses in the correct responses and reaction times. The grade differences were found as to strategies used in this problem. While lower grade children were inclined to use spatial abilities, higher grade children were apt to use numerical and verbal abilities. Aoki (1989, 37, 359-364) investigated the relationship between judging addition of weights and judging conservation of volume. The results showed that a U-shaped curve was found again though sex differences were not observed. It was also found that volume conservation achievement did not always explain every phenomenon as to this curve.

There are many areas or aspects to be studied more at the elementary school level. Children's prosocial or altruistic behavior is one of the most important areas. None of the studies of this area were done with elementary school children. More studies regarding class- 
room instruction for language, math, science and the like should be done by educational psychologists. In other words, educational psychologists should do more research on school curricula and classroom in. structions in each school subject.

\section{Adolescent and Adult Studies.}

Categorizing many articles here is not easy, but the present author tried to divide them into the following five parts. They are (a) ego and self, (b) learning and problem solving, (c) prosocial behavior, and (d) other specific topics.

\section{(a) Ego and Self.}

Nagao (1989, 37, 71-77) attempted to develop ego developmental crisis state scale (ECS). The following are the main results. Senior high school students scored higher on self examination problems and self aware symptoms than any other group. Self examination problem score were related to self aware symptom score. While these were differences between grades on self examination problem scores, there were no differences between males and females, or between grades on self aware symptoms. A study of both sides of its own self was done by Yamamoto (1989, 37, 302311). Yamamoto investigated some developmental trends and sex differences in adolescents and adults, and the relationships between each phase of self and Self-Esteem. There are two phases of self, Connected and Separated $(\mathrm{c} / \mathrm{s})$. The results indicated that both scores of $\mathrm{c} / \mathrm{s}$ and Self-Esteem were positively affected on the level of Self-Esteem. It was believed that the powers and modes of effectiveness were seen as different between sexes and along different developmental life stages.

(b) Learning and Problem Solving.

Fushimi and Magara (1989, 37, 270-275) investigated the effects of explaining the significance of classifying objects upon learning their features. It was found that advance information facilitated deep learning of the text. It made learning more significant. They discussed this from the viewpoint of science education. Toyota (1989, 37, 234-242) investigated the effects of autobiographical elaboration on incidental learning. He found that the quantity and the quality of personal experiences determined the effectiveness of autobiographical elaboration. Magara (1989, 37, 312-319) studied the typicality effect in problem solving, and Kobayashi (1989, 37, 374-380) examined the mental representation of a problem and the intuitive judgments on the initial process of problem solving.

(c) Prosocial Behavior.

Yokotsuka (1989, 37, 158-162) attempted to develop a scale of prosocial behavior for junior and senior high school students. Five factors were derived from the factor analysis of twenty items. They were as follows: (1) helping other family members, (2) social service and donations, and three other factors concerned with helping friends, (3) behavioral situations, (4) learning situations, and (5) psychological situations. The score of this scale related to positively to the score of the benevolence value and negatively to that of the independence value; the score related positively to the empathy scale, self-consciousness scale, selfmonitoring scale and social skill scale.

(d) Other Specific Topics

Takai (1989, 37, 386-391) examined the modality and text type effects on memory and understanding. Recall and various self-rating measures reflected different aspects of story processing. Nakagaki (1989, 37, 36-45) examined the degenerative effects on logical reasoning in the abstract four card problem. He concluded that the matching bias in the abstract four card problem could be better interpreted from the viewpoint of degeneration theory. Mino (1989, 37, 243-251) examined the relationship between test performance, the arrangement of test questions, and the degree of test anxiety. The results suggest that it is necessary to take the arrangement of test questions into consideration especially when a test involves very difficult questions in order to keep high-anxious students from being placed in an unfavorable situation.

Endo (1989, 37, 61-66) investigated the influence of interlocutor's operability on the use of Japanese demonstrative "so". The first hypothesis was that subject's use of "so" would be greatest when the distance from subjects to the referent was relatively far but that from the referent to the experimenter was considered as relatively short. The second hypothesis was that subjects' use of "so" would be higher under the pointer-pointing condition than under the fingerpointing one. These hypotheses were confirmed. Endo 
(1989, 37, 20-28) studied the willingness of self: disclosure and the deviation from normative selfdisclosure in disclosure situations. It was suggested that the willingness score could be a valid index for the discloser's mental health and that the deviation score reflected the discloser's public aspects of selfconsciousness. Banzai (1989, 37, 107-116) investigated the interpersonal relationships between leaders and followers in senior high school soccer teams. It was found that the effects of leadership was mediated by the follower's individual personality characteristics. Tanaka (1989, 37, 365-373) attempted to make a manual of Personalized System of Instruction (PSI) for Japanese college courses. Further research on the PSI which is called the Keller Plan is needed by educational psychologists.

Although no studies regarding suicide and bullying were found. These topics are still of importance for educational psychologists.

(4) Age Adult Studies.

There are only two studies concerning elderly people. One is Ohkawa's study, and the other is Nakazato and Shimonaka's one. Ohkawa (1989, 37, 100. 106) investigated the relationship between 27 factors constituting six domains of "non-normative life events" and intellectual abilities such as fluid, crystallized, and general. The participants were 61 makes, aged 65 to 75 . As a results of correlational analysis, it was found that 3 factors in "non-normative life events" were related to fluid ability, 6 factors were related to crystallized ability and 8 factors were related to general ability. Nakazato and Shimonaka (1989, 37, 172-178) investigated the development of anxiety. The subjects were 1,234 males and females, aged 25 to 92 . The State-Trait Anxiety Inventory was administered to the subjects. It was found that anxiety declined linearly throughout the adult life span. Sex difference was also observed in trait anxiety, with females showing higher anxiety than males while a profession effect was found for males, an education effect was found for females.

(5) Other Specific Studies.

(a) Mentally Retarded.

Kawada et al. (1989, 37, 78.83) investigated the method of estimating responsive behaviors of pro- foundly retarded persons. They suggest that the method of estimating responses of profoundly retarded persons through conditional probability might be effective in examining responsive behaviors of profoundly retarded persons. Matsumoto (1989, 37, 117125) investigated the process of sentence comprehension by mentally retarded individuals. The results indicated that (1) a semantic strategy was frequently recognized, (2) most subjects pointed to the actor on the card while the subjects chose one of the two cards and (3) the subjects who used the word order strategy pointed to the item on the card according to both the semantic rule on the card and word order rule in the sentence.

(b) Measurement and Statistics.

Toyoda (1989, 37, 283-285) proposed three methods for estimating the reliability coefficient under the Item Response model. The first method may be used for the item selection. The second method gives the upper found of the reliability coefficient estimate. The third method may be used for the estimate of reliability coefficient, only with the sample mean and variance of the estimated values on the latent trait. Toyoda (1989, 37, 67-70) attempted to propose a least-squares method for parameter estimation using Fisher's ztransformation in correlation structure analysis. An advantage of this method is that the residuals are normally distributed and their variances are homogeneous. He found that this method is shown to have less significant errors of parameter estimates than the unweighted least squares method.

(c) Teacher Study.

Misumi and Yamori (1989, 37, 46-54) measured class-teachers' leadership behaviors in a junior high school, based on PM leadership model and examined its validity by investigating the relationship between leadership types and pupil's morale variables. The following are the main results. (1) By a factor analysis of leadership items, six factors were found and twenty-four items were selected to measure $P$ and $M$ behaviors. (2) By a factor analysis of morale items, four factors were found as external criterion variables. (3) Teachers were classified into four types, PM-type, P-type, M-type, pm-type, depending on $\mathrm{P}$ and $\mathrm{M}$ scores. (4) Pupils' school morale came highest under PM-type, 
followed by M-type or P-type, and the lowest under pm-type.

Nasu (1989, 37, 84-95) overviewed studies of Bernard Weiner's attribution theory of achievement motivation.

3. Faces of Educational Psychology.

The present author gave an invited talk on the faces of educational psychology at the 31st Annual Convention of Japanese Association of Educational Psychology held at the University of Hokkaido (Sukemune, 1989). He first proposed at the Annual Convention of this Association that there should be at least two faces of educational psychology about ten years ago. One is the face of fundamental study, and the other is the face of educational practice. He is still confident that educational psychology should, at least, have these faces. It may be possible that an educational psychologist has always these two faces, but generally most educational psychologists should only have either the fundamental research face or the educational practice face. Since then, he has had related valuable experience as to this point. He served two terms as principal of Hiroshima University Demonstration Kindergarten as an additional post. He has also had good opportunities to do research on educational practice with teacher of kindergartens, day nurseries, and grade schoels (Sukemune, 1988). From these experiences, he proposed a third face of educational psychology at the University of Hokkaido in 1989. The two faces which I proposed first each are concerned with the research to be done by educational psychologists themselves with their own ideas. However, the third face is quite different from the previous, two faces in terms of finding and establishing the themes. A theme or a proposal should come out from the interaction (discussion) of educational psychologists and school teachers. Both teachers and educational psychologists are primarily responsible for the proposal. The third face is of very great importance. In the present author's opinion more research on educational practices in this third face is needed.

There are at least three important points for educational psychologists to be aware of : First, educational psychologists should know of antecedent studies in the literature. Second, educational psychologists should know of children's present daily lives in schools and homes in modern culture and society. Finally, educational psychologists should develop their own ideas on the base of the first and second points. It might be said that if the present author would be asked as to the adequacy of these points in Japanese educational psychology, he would answer the second and the third points are the ones which are in need of help.

\section{References}

Anan, A. 1989 The process of sharing rule in children's play. Japanese Joumal of Educational Psychology. 37 (3), 218-224.

Aoki, T. 1989 Relation between judging addition of weight and conservation of volume. Japanese Jour nal of Educational Psychology, 37 (4), 359-364.

Banzai, T. 1989 Leadership effects as a function of follower's personality characteristics. Japanese Journal of Educational Psychology, 37 (2), 107-116.

Endo, K. 1989 The willingness of self-disclosure and the devitation from normative self-disclosure in disclosure situations. Japanese Journal of Educational Psychology, 37 (1), 20-28.

Endo, M. 1989 The influence of interlocutor's operability on the use of Japanese demonstratives SO. Japanese Journal of Educational Psychology, 37 (1), 61-66.

Fujimoto, K. 1989 Specific cues in perspective-taking task (I). Janese Journal of Educational Psy. chology, 37 (4), 337-344.

Fujita, Y. 1989 The mechanism emergence and development of the synchrony pattern demonstrated between the child's and the adult's verbalizations and hand-arm actions in "Jan-Ken" movement. Japanese Journal of Educational Psychology, 37 (2), 135-143.

Furuya, K., \& Tashiro, Y. 1989 Ways preschool children relate to characters in picture book. Japanese Jourmal of Educational Psychology, 37 (3), 252-257.

Fusimi, Y., \& Magara, K. 1989 Effects of the advance information about significance of classfication on learning. Japanese Journal of Educational Psychology, 37 (3), 270-275.

Haryu, E. 1989 What facilities learning to read characters by children. Japanese Journal of Educational 
Psychology, 37 (3), 264-269.

Hatta, T., \& Kanba, M. 1989 Effects of abacus training on hemisphere specialization in children. Japanese Journal of Educational Psychology, 37 (4), $320-326$.

Hosaka, C. 1989 A study concerning the influential process of confidence performance and causal attribution in arithemetic aspect. Japanese Journal of Educational Psychology, 37 (3), 259-263.

Kawada, M., Koike, T., \& Katada, A. 1989 A study on method of estimating responsive of profoundly retarded persons through conditional probability. Japanese Journal of Educational Psychology, 37 (1), 78-83.

Kinoshita, Y. Determinants of strategy choices in decoding an order of preference for a group. Japanese Journal of Educational Psychology, 37 (2), 144-150.

Kitahara, Y. 1989 A developmental study segregation in visual perception of figures. Japanese Journal of Educational Psychology, 37 (3), 198-207.

Kobayashi, J. 1989 Mental representation on a problem and intuitive on initial process of problem solving. Japanese Journal of Educational Psychology, 37 (4), 374-380.

Magara, K. 1989 Typicality effects in problem solving. Japanese Journal of Educational Psychology, 37 (4), 312-319.

Matsumoto, T. 1989 Process of simple sentence comprehension of mentally retarded individuals. Japanese Journal of Educational Psychology, 37 (2), 117-125.

Matsumura, N. 1989 The representation of occlusion and solid figures in young children's drawings. Japanese Journal of Educational Psychology, 37 (3), 225-223.

Mino, M. 1989 On test anxiety and performance: Differential effects of arrangement and difficulty of questions. Japanese Journal of Educational Psychology, 37 (3), 243-251.

Misumi, J., \& Yamori, K. 1989 A study on validity of measurement scảle of teacher's leadership behavior in the junior high school. Japanese Journal of Educational Psychology, 37 (1), 46-54.

Nagao, H. 1989 An approach to measure ego develop- mental crisis state during adolescence. Japanese Journal of Educational Psychology, 37 (1), 71-77.

Nakagaki, A. 1989 Degeneration effects on logical reasoning in the abstract four cards problem. Japanese Journal of Educational Psychology, 37 (1), 36-45.

Nakayama, K. 1989 Children's motivational orientations and their perceptions of teacher's attitudes. Japanese Journal of Educational Psychology, 37 (3), 276-282.

Nakazato, K., \& Shimonaka, Y. 1989 A cross-sectional studty of development of anxiety in adult lifespan. Japanese Journal of Educational Psychology, 37 (2), $172 \cdot 178$.

Nasu, M. 1989 A study of Weiner's attribution theory of achievement motivation. Japanese Journal of Educational Psychology, 37, 84-95.

Niwa, Y. 1989 Attribution-affect processes in achievement related contexts in school age children. Japanese Journal of Educational Psychology, 37 (1), 11-19 .

Ohkawa, I. 1989 A study of relationships between 'non-normative life events' and intellectual abilities in elderly people. Japanese Journal of Educational Psychology, 37 (2), 100-106.

Onose, M. 1989 Effects of a copying size on handwriting skills. Japanese Journal of Educational Psychology, 37 (2), 186-190.

Sakurai, S. 1989 The effects of the instruction of evaluation and the expectation of extrinsic rewards on children's intrinsic motivation. Japanese Journal of Educational Psychology, 37 (1) 29-35.

Shiomi, K., \& Nakashima, H. 1989 The development of the ability of mental relation in children and its relationship with mental abilities. Japanese Journal of Educational Psychology, 37 (1), 55-60.

Sogon, S., Masutani, M., Imakawa, S., \& Nakamichi. M. 1989 On mother's emotional expression styles and thirteen-month-old infant's emotional behavior. Japanese Journal of Educational Psy. chology, 37 (4), 353-358.

Sugie, S., \& Kajita, M. 1989 The effects of teaching activities of children. Japanese Journal of $E d r$. cational Psychology, 37 (4), 381-385. 
Sugimura, S. 1989 Understanding the movement of covered objects in young children. Japanese Journal of Educational Psychology, 37 (2), 179-185.

Sukemune, S. 1989 Development, educational care of altruistic behavior. Proceedings of the 30th Annual Convention of Japanese Association of Educational Psychology. (p. 38, symposium).

Sukemune, S. 1989 Does educational psychology have two or three faces. Proceedings of the 31th Annual Convention of Japanese Association of Educational Psychology. (p. 35, invited talk).

Taira, N., Takei, S., \& Ogino, M. 1989 Measurement of infants' and toddlers' languge comprehension by an adaptive questionnaire. Japanese Journal of Educational Psychology, 37 (4), 392-399.

Tajika, H., \& Ishida, J. 1989 Children's understanding and memory for arithemetic word problems. Japanese Journal of Educational Psychology, 37 (2), 126-134.

Takai, K. 1989 The presentation modality and text type effects on story memory and understanding. Japanese Journal of Educational Psychology, 37 (4), 386-391.

Tanaka, S. 1989 A manual of PSI applied in Japanese university course. Japanese Journal of Educational Psychology, 37 (4), 365-373.

Toyama, N. 1989 Mental speech in mother-toddler picture book reading. Japanese Journal of Educational Psychology, 37 (2), 151-157.

Toyoda, H. 1989 A least-squares solution for correlation structure analysis with Fisher's $z$ transformation. Japanese Journal of Educational Psychology, 37 (1), 67-70.

Toyoda, H. 1989 The models for estimating the reliability coefficient under item response model. Japanese Journal of Educational Psychology, 37 (3), 283-285.

Toyota, H. 1989 Effects of autobiographical elaboration on incidental learning. Japanese Journal of Educational Psychology, 37 (3), 234-242.

Tsukamoto, S. 1989 Effects of interaction of children's prosocial and social standards on their self-

1 evaluation criteria. Japanese Journal of Educational Psychology, 37 (3), 208-217.

Uchida, N. 1989 The development of "deficit- complement" schema in a semantic integration of narrative sequences in an abstract drawing story. Japanese Journal of Educational Psychology, 37 (4), 327-336.

Watanabe, Y. 1989 Relationship of development between distributive justice and authority in childhood. Japanese Journal of Educational Psy. chology, 37 (2), 163-171.

Watanabe, M., \& Yamamoto, R. 1989 Making a test of ego development using sentence completion method: Translating and simplifying the Loevinger's WU-SCT. Japanese Journal of Educational Psychology, 37 (3), 286-292.

Yamamoto, R. 1989 A study on both sides of its own self: An investigation of developmental trends from adolescence to adulthood and sex difference. Japanese Journal of Educational Psychology, 37 (4), 302-311.

Yamane, R. 1989 Integrating process of communicative mode in demanding situation during preverbal period. Japanese Journal of Educational Psychology, 37 (4), 345-352.

Yokotsuka, R. 1989 An attempt to construct a scale of prosocial behavior for high school students. Japanese Journal of Educational Psychology, 37. (2), 158-162.

Yoshimizu, C. 1989 The development of symbolic play and its relation to language development and mother-child communication in the third year child. Japanese Journal of Educational Psychology, 37 (1), 1-10.

The Annual Report of Educational Psychology in Japan, 1989, 28.

Proceedings of the 30th Annual Convention of Japanese Association of Educational Psychology. $(30,1988)$.

Proceedings of the 31th Anmual Convention of Japanese Association of Educational Psychology. (31, 1989).

The present author is indebted to my friend, Professor Danny Steinberg, Surugadai University, for his kind help in the English version of this article, and is also indebted to my graduate student, Mr. Toshiyuki Shiraishi, Hiroshima University, for his kind wordprocessing this anuscript. 